\title{
Taming the tide of HIV and TTI scourge in Sub-Saharan Africa using autologous blood transfusion
}

\author{
Collins Ogbonna Nwabuko ${ }^{* *}$, Martin Anazodo Nnoli², Okoh Dorothy Adaunwo ${ }^{3}$ and Innocent ljezie Chukwuonye ${ }^{4}$ \\ *Correspondence: ogbollins2002@yahoo.com \\ ${ }^{1}$ Abia state University Teaching Hospital/Federal Medical Centre, Department of Haematology, Abia, Nigeria. \\ ${ }^{2}$ University of Calabar Teaching Hospital, Department of Pathology\&Forensic Medicine, Calabar, Nigeria. \\ ${ }^{3}$ Braithwaite Memorial Specialist Hospital, Department of Pathology, Port Harcourt, Nigeria. \\ ${ }^{4}$ Federal Medical Centre, Department of Internal Medicine, Umuahia, Nigeria.
}

\begin{abstract}
Background and objective: The re-emergence of Transfusion Transmissible Infections (TTIs) and Human Immunodeficiency Virus (HIV) through allogeneic blood transfusion has made the subject of autologous blood transfusion to begin to gain adequate attention globally in recent times. This study aimed at enlightening the public on the importance of Autologous blood transfusion as a strategy in curbing HIV, TTI and allogeneic blood transfusion reaction in sub-saharan Africa where poor screening of blood contributes to their spread. To ascertain the suitability of autologous blood transfusion as a safe blood transfusion strategy, the whole essence of which is to achieve better quality of care for our patients.

Methodology: The study was divided into 2 parts, one was questionnaire-driven and the other was on the use of Autologous blood transfusion.A total of 40 patients (30 of whom were HIV sero-positive while 10 were HIV sero-negative) aged between 19-55years were randomly recruited for this study in the Dept of Haematology, University of Benin and Port Harcourt Teaching Hospitals between 1997-2008. Thirty (30) of the patients, who had previously received allogeneic blood transfusions and were HIV seropositive, were given only questionnaire while the $10 \mathrm{HIV}$ sero-negative patients received Autologous blood transfusion following surgical procedures.

Result: A-6-month pre- and post-surgical retroviral screening of the ten (10/25\%) patients who received autologous blood transfusion revealed that they remained HIV I\&II sero-negative with no TTI or blood transfusion reaction recorded. One (2.5\%) of the allogeneic group who was apparently HIV negative prior to surgery was found HIV sero-positive 6 months following transfusion of unscreened blood.

Conclusion: There is a place for autologous blood transfusion as a safe blood transfusion strategy in low income countries of sub-Saharan Africa.

Keywords: Autologous blood transfusion (ABT), human immunedeficiency virus (HIV), transfusion transmissible infection (TTI), Sub-Saharan Africa
\end{abstract}

\section{Introduction}

One of the public health challenges of this generation remains the prevention of HIV/AIDS and Transfusion transmitted infections. The HIV burden globally is about 33.2 million people. Sub-saharan Africa appears to be the most affected with about $68 \%$ (about 22 million) of the people living with HIV/AIDS worldwide residing in that region. Apart from sexual and other routes of transmission, unsafe blood transfusion contributes significantly to the transmission of HIV and various transfusion-transmitted infections (TTIs) in sub-Saharan Africa. According to the WHO blood safety report, in Africa, 250-500 people are newly infected with HIV each day as a result of unsafe blood transfusion, hence the need for safety blood transfusion practice becomes necessary in our national blood transfusion centres $[\mathbf{1 , 2}]$.

Autologous blood donation is the process of donating ones own blood prior to an elective surgical and the introduction of medical procedures to avoid or reduce the need for an allogeneic blood transfusion from voluntary blood donors.
Autologous blood transfusion involves collection and reinfusion of the patient's own blood or blood components during blood demanding surgical and medical procedures. ABT grew in popularity in response to the recognition of transfusion-transmitted HIV infectionand lack of effective screening procedures which is peculiar to resource-constraint areas of sub-Saharan Africa [3].

ABT has been performed for more than 150years [4]. During the early to mid 1980s when the risk of allogeneic blood transfusion-transmitted HIV was as high as 1:100 in some areas [5] and no test existed to detect its presence, interest in and demand for this life saving alternative increased. Studies have demonstrated that fear of contracting an infectious disease, particularly HIV, from allogeneic blood transfusion has been a primary motivating factor in the decision to donate autologous blood [4,6-9].

There are about four types of autologous blood donations, namely:Pre-operative autologous blood transfusion (PABT), otherwise known as Pre-deposit autologous transfusion, 
Nwabuko et al. Hematology and Leukemia 2013,

http://www.hoajonline.com/journals/pdf/2052-434X-1-7.pdf

doi: $10.7243 / 2052-434 X-1-7$

Acutenormo-volemichemodilution (ANH), Intraoperative blood salvage and Post-operative blood salvage.

In PABD, units of blood are drawn from a patient usually starting about five weeks before an elective surgery and stored for transfusion at the time of the surgery. Pre-deposit autologous blood transfusion can eliminate the transfusiontransmitted infections and the immune risk associated with allogeneic blood transfusion. The major limitation of this ABT method is that not all the candidates are eligible to benefit from it. It requires adequate time to collect the specific number of units of blood as the amount of blood stored via this method may not be enough to replace the unexpected blood loss. Blood for PABD can be stored from 40 days to 10 years for rare blood type.This method of ABT is commonly practiced in developed countries [10].

In Acute normo-volemichemodilution (ANH), blood is collected at the start of surgery and the fluid volume lost is replaced with appropriate volume expander and finally, stored blood is re-infused after surgery. The goal of ANH is to reduce RBC loss during surgery. Blood is stored at room temperature for up to 6 hours and re-infused after surgery. It is not for anemic patients or those with poor kidney function.

In intra-operative blood salvage (IOBS), blood is salvaged from the surgical field during the operation for re-infusion during or after the surgical procedure. It involves recovering the patients' own blood from operation field or bleeding wound, and re-infusing it later on. Special devices are required for the collection, filtering and draining blood into the transfusion bag. It is used for trauma or surgical patients with severe blood loss and the blood must be re-infused within 6hours.

Post-operative blood salvage (POBS) involves blood collection by drainage of the operative field after the surgical procedure is completed. This blood is re-transfused after surgery [11].

There are surgical procedures that can benefit from autologous blood transfusion. They include:major orthopaedic surgeries, cardiovascular surgeries, obstetric surgeries (hysterectomy especially in uterine fibroid and some ovarian tumours), radical prostatectomy, mastectomy, and gastric surgery. Blood derived from ruptured organs or the surgical field can be collected from the thoracic or abdominal cavities.

In the USA, the number of autologous collection peaked in 1992 (about 1,117000), representing 8.5\% of the blood supply. By 1997, autologous units collected had declined to 611,000 representing $4.9 \%$ of blood supply [12]. The reasons for the decline in autologous donations has been linked to improved screening procedures, increased costs, patient inconvenience, possible clerical errors and laws regarding autologous blood transfusion [13-15].

However, despite the aforementioned challenges, ABT remains a staple of clinical transfusion medicine practice. It is the safest product available, providing patients with a source of blood free of infections that may still be escaping the screening process of allogeneic blood supply. If a TTI emerges in the future that is capable of evading screening procedures and capturing the public's attention, there would be a likely resurgence of autologous blood transfusion.

About $5-10 \%$ of HIV burden in sub-Saharan Africa is caused by allogeneic blood transfusion [16], hence the need to have safe blood becomes very important if we must have to reduce HIV epidemic in the region. There is paucity of statistics of $A B T$ in sub-saharan Africa. However, very few studies have been done in sub-Saharan West Africa where IOBS method of autotransfusion was used to correct anaemia due to haemorrhage from ruptured ectopic pregnancy in two hundred and twelve patients (212). This study showed that autologous blood transfusion did not only improve the haemoglobin concentration of the severely anaemic patients but was a safe method of blood transfusion with minimal TTIs [17].

This study is aimed at enlightening the public about $A B T$ and its usefulness as a safe blood transfusion practice in resourcelimited settings such as those in sub-Saharan Africa. It is also aimed at enunciating the importance of autotransfusion in correcting anaemias, minimizing the spread of TTI and blood transfusion reaction which usually characterize allogeneic blood transfusion in such settings due to poor screening procedures.

\section{Methodology}

This is a retrospective study carried out from January 1998 to December, 2008 in two tertiary institutions namely Universities of Benin and PortHarcourt Teaching Hospitals (UBTH and UPTH) located in the Niger Delta region of Nigeria. Each of the tertiary institutions is a-1000-bed hospital. All the patients were recruited at the department of Haematology in collaboration with the Obstetrics and Gynaecology department where we derived our patients for autologous blood transfusion. They included both HIV-seropositive (30), who previously received allogeneic blood transfusion, and HIV-seronegative (10) patients, who were autotransfused (simple intra-operative blood salvage method of autologous blood transfusion). The HIV sero-positive and negative were given questionnaire to ascertain basically their sexual activities, blood transfusion histories, and other possible risk factors.

Pre-transfusion HIV screening was done on the patients (10) by double Enzyme Linked Immunosorbent Assay (ELISA) technique using Genescreen (Sanofi, Pasteur) and Biorad test kits, respectively, while confirmation was by the Immunocomb method (Organic,Isreal). Statistical analysis was by SPSS version 16 .

\section{Results}

A total of forty (40) aged 19-55 years (mean age 34.1 \pm 8.1 years were studied, out of which 30 (75\%) were females and 10 (25\%) males (M:F ratio was 1:3). About $10 \%$ of the study population who tested sero-negative to HIV $1 / 2$ were auto-transfused.All the patients who underwent autologous blood transfusion (IOBS) were females (Haemoperitoneum following ruptured 
Nwabuko et al. Hematology and Leukemia 2013,

Table 1. Baseline data of autotransfused patients.

\begin{tabular}{|c|c|c|c|}
\hline Criteria & Male(n) & Female(n) & Total(n) \\
\hline gender & -- & 10 & 10 \\
\hline \multicolumn{4}{|l|}{ Marital status: } \\
\hline single & -- & 5 & 5 \\
\hline married & -- & 5 & 5 \\
\hline separated & -- & -- & -- \\
\hline \multicolumn{4}{|l|}{ Sexual history: } \\
\hline positive & -- & 2 & 2 \\
\hline negative & -- & 8 & 8 \\
\hline ns & -- & -- & -- \\
\hline \multicolumn{4}{|l|}{ Hiv status: } \\
\hline positive & -- & -- & -- \\
\hline negative & -- & 10 & 10 \\
\hline autologous blood & -- & 10 & 10 \\
\hline \multicolumn{4}{|l|}{ 6/12 pre.rvs: } \\
\hline $\mathrm{a}$ & -- & 8 & 8 \\
\hline na & -- & 2 & 2 \\
\hline ns & -- & -- & -- \\
\hline \multicolumn{4}{|l|}{ Pre.bt: } \\
\hline yes & -- & -- & -- \\
\hline no & -- & 10 & 10 \\
\hline \multicolumn{4}{|l|}{ Blood screening: } \\
\hline s & -- & 10 & 10 \\
\hline us & -- & -- & -- \\
\hline ns & -- & -- & -- \\
\hline $6 / 12$ post.rvs & -- & All autotransfused & $\begin{array}{c}\text { Tested } \\
\text { negative }\end{array}$ \\
\hline $\begin{array}{l}\text { pre-operative hb concentration of } \\
\text { abt patients }\end{array}$ & -- & $75.4 \pm 16.5 \mathrm{~g} / \mathrm{l}$ & -- \\
\hline $\begin{array}{l}\text { average volume of blood salvaged } \\
\text { for abt patients }\end{array}$ & -- & $701 \pm 367 \mathrm{mls}$ & -- \\
\hline $\begin{array}{l}\text { post-operative hb concentration of } \\
\text { abt patients ( } 6 \text { days after). }\end{array}$ & -- & $87.6 \pm 11.5 \mathrm{~g} / \mathrm{l}$ & -- \\
\hline
\end{tabular}

Key: NS=Not Sure; A=Aware; NA=Not Aware; 6/12=6months; PRE. RVS=Pre-Surgical Retroviral Screening; POST.RVS=Post-surgical Retroviral screening; PRE-BT = Previous Blood Transfusion; $\mathrm{s}=$ screened; us=unscreened;ns=not sure.

ectopic gestation) (Tables 1 and 2).

Two (20\%) and 12 (40\%) of the autotransfused and allogeneic study populations, respectively, had positive sexual history. In 2 (7\%) of the allogeneic group, the sex life was not contributory.About 16 (53\%) of the allogeneic patients were not sure of their sex life (Tables 1 and 2).

About $7(23 \%)$ and $8(80 \%)$ of the allogeneic and autologous transfused study populations were awareof their retroviral status prior to surgery and the history of blood transfusion, respectively. Ten (33\%) and $2(20 \%)$ of the allogeneic and autologous groups, respectively, were not aware of their HIV status six months prior to surgery/blood transfusion.

Ten (100\%) and 16 (53.3\%) of the autologous and allogeneic study populations, respectively, under went proper blood screening while $3(10 \%)$ of allogeneic were unscreened. Eleven (36.7\%) of allogeneic group were not sure of blood screening
Table 2. Baseline characteristics of allogeneic transfused HIV sero-positive patients.

\begin{tabular}{lccc}
\hline Criteria & Male & Female & Total \\
\hline gender & 10 & 20 & 30 \\
\hline Marital status: & & & \\
\hline single & -- & -- & -- \\
married & 8 & 15 & 23 \\
separated & 2 & 5 & 7 \\
\hline Sexual history: & & & \\
\hline positive & 5 & 7 & 12 \\
negative & -- & 2 & 2 \\
ns & 5 & 11 & 16 \\
\hline Hiv status: & & & \\
\hline positive & 10 & 20 & 30 \\
negative & -- & -- & -- \\
autologous blood & -- & -- & -- \\
\hline 6/12 pre.rvs: & & & \\
\hline a & 5 & 2 & 7 \\
na & -- & 10 & 10 \\
ns & 5 & 8 & 13 \\
\hline Pre-bt (allogeneic): & & & \\
\hline yes & 10 & 20 & 30 \\
no & -- & -- & -- \\
\hline Blood screening: & & & \\
\hline s & 4 & 12 & 16 \\
us & -- & 3 & 3 \\
ns & 6 & 5 & 11 \\
\hline
\end{tabular}

Key: NS=Not Sure; A=Aware; NA=Not Aware; 6/12=6months; PRE. RVS=Pre-Surgical Retroviral Screening; POST.RVS=Post-surgical Retroviral screening; PRE-BT = Previous Blood Transfusion; $s=$ screened; us=unscreened;ns=not sure .

status. One (3\%) patient who had received unscreened allogeneic blood (currently is HIV positive), and claimed to be HIV-sero-negative prior to surgery, became HIV-positive about six months post operation.

The mean pre-operative haemoglobin concentration of auto-transfused patients was $75.4 \pm 16.5 \mathrm{~g} / \mathrm{L}$ while a mean blood volume of $701 \pm 367 \mathrm{ml}$ was salvaged. The mean haemoglobin concentration reached $87.6 \pm 11.5 \mathrm{~g} / \mathrm{L}$ 6days post-operatively.

Post-operative retroviral tests (HIV I/II) were negative in the $10(100 \%)$ auto-transfused population six months $(6 / 12)$ follow-up.

\section{Discussion}

This study, although constrained by a small sample size, has shown that there is a significant gender inequality in participation and attendance of HIV clinic in our environment. The increase in female:male ratio $[(F: M=3: 1) ; p<0.05]$ shows that more females tend to seek for medical care compared to their male counterparts when infected with Human Immunodeficiency Virus (HIV). This is in keeping with previous studies done on HIV whereby female gender tends to be demographically higher than that of the male [18]. 
Nwabuko et al. Hematology and Leukemia 2013,

http://www.hoajonline.com/journals/pdf/2052-434X-1-7.pdf

doi: $10.7243 / 2052-434 X-1-7$

This study also witnessed more married couple participation compared to single or separated/divorced counterparts. This could be attributable to the fact that the married patients would prefer to seek medical care to be healthy to take care of the growing children compared to single or separated/ divorced counterparts who may not present to clinic early because of social stigma.

The very few patients with positive sexual history $(2 / 20 \%$ for autotransfused and $12 / 40 \%$ for allogeneic) may not be reflective of the actual size. This is because most patients do not like to divulge all their sexual histories so that they would not be branded to be promiscuous. They would like to build up some levels of confidence before they can open up to their clinicians.

This study shows that less than half (23\%)of the allogeneic population were aware of their HIV status. This was similar to the data by US Preventive Services Task Force (USPSTF) in which they found that nearly one quarter of persons with HIV infection are unaware of their positive status in the United states [19] This shows that much work still needs to be done in creating the awareness of HIV screening in the public, possibly through voluntary counseling and testing (VCT). According to current WHO recommendations, early testing and treatment for HIV contribute significantly in reducing the rates of HIV infection, morbidity and mortality, hence prolonging the survival rate of HIV patients [20].

Although 16(53.3\%)of the allogeneic group had their blood previously screened as against $3(10 \%)$ and $11(36.7 \%)$ of the same group who were unscreened or not sure of being previously screened, respectively, much attention needed to be paid on the primitive blood screening processes in subSaharan Africa. Most of the screened blood in our regional laboratories are antibody-based and so lack the capacity to detect infected blood at the window phase. This could be the possible reason why one of the HIV sero-positive patients who was apparently HIV sero-negative before she was transfused unscreened blood in a rural hospital, became HIV-sero-positive six months post-transfusion. HIV-tainted blood is being used to transfuse African patients when there are no options left [21]. Screening of blood is essential but remains absent in many low and middle-income countries. There is, therefore, need for the government and other donor agencies with passion for HIV and transfusion transmissible infections to re-consider policies that will make all blood screening processes to be antigen-based in our regional laboratories. By this policy, the viruses can be detected at the window phase, hence minimizing transfusion transmissible infections.

The small sample size of autotransfused patients over ten years shows that autologous blood transfusion is not a common practice in sub-Saharan Africa. Similarly, the fact that there was only one type of autologous blood transfusion (intra-operative blood salvage) in this study shows that there is paucity of enlightenment of the public on the importance of the later as a strategy of minimizing transfusion-transmissible
HIV,transfusion-transmissible infections and blood transfusion reactions in resource-poor centres such as those in the Niger delta region of Nigeria. This study also reflects actually what happens in other countries in sub-Saharan Africa where Pruli,G. et al., carried similar multicentred study using patients with ruptured ectopic pregnancy [17]. Although it is becoming relativelyuncommon in developed countries due to current advances made in the blood screening processes, autologous blood transfusion constitutes about 5-10\% of the total annual blood transfusion in the United States [12-14].

There is, therefore, need to re-consider the concept of autoogous blood transfusion as a safe blood transfusion strategy in our national blood transfusion policy since our screening processes have not remarkably improved and we are still struggling to combat remunerated allogeneic blood donation in our various regional blood banks [22-24].

The mean blood volume of $701 \pm 367.1 \mathrm{mls}$ salvaged from auto-transfused patients and the rise in mean pre-operative haemoglobin concentration from $75.4 \pm 16.5 \mathrm{~g} / \mathrm{L}$ (preoperatively) to $87.6 \pm 11.5 \mathrm{~g} / \mathrm{L}$ six days post-operation shows that intra-operative blood salvage method of autologous blood transfusion can also be a useful alternative to allogeneic blood transfusion in emergency conditions if properly harnessed. Similar study by Pruli et al., involving two hundred and twelve patients (212) in sub-Sahelian West Africa shows an average of $681 \pm 389 \mathrm{mls}$ of salvaged blood and a post-operative haemoglobin concentration of $84.7 \pm 10.5 \mathrm{~g} / \mathrm{L}$ (pre-operative haemoglobin concentration $=70.6 \pm 18.7 \mathrm{~g} / \mathrm{L}$ ). However, unlike the study of Pruli et al., in which twenty-two patients, half of whom had a life-threatening haemodynamic state with severe anaemia,were given donor blood,none of our ten (10) auto-transfused patients was given donor blood. Although they were moderately anaemic 6 days post-operation, they were discharged on oral haematinics.

The autotransfused patients underwent retroviral screening (HIV I/II) six months after sugery and they all tested HIV seronegative with no untoward outcomes (i.e., Blood transfusion Reaction) attributable to the re-infusion seen in any of them. This further shows that autologous blood transfusion is a safe and efficient strategy of curbing transfusion transmissible infections (including HIV infection)and blood transfusion reactions in low income countries like ours where proper blood screening processes are still crude and unavailable.

\section{Conclusion}

This study has shown that autologous blood transfusion is a safe blood transfusion strategy. It can serve asan alternative for allogeneic blood transfusion for some medical/surgical conditions including some elective surgical cases in resourcepoor centres, such as those in sub-Saharan Africa, where commercial (paid) blood donation constitute major source of blood supply in the national blood transfusion centres. It should not only be scaled up in our regional blood banks but should be recommended in the policy guidelines for 
Nwabuko et al. Hematology and Leukemia 2013,

safe blood transfusion practices in our regional hospitals as done in high income countries.

Finally, there is need to scale up the standard of screening processes in the regional laboratories in sub-Saharan Africa since poorly screened allogeneic blood transfusion contributes significantly to the transmission of the deadly virus, HIV and other infections in the region.

\section{Limitation}

Only one type of autologous blood transfusion was recruited throughout the study period.We could not explore the outcome of other types of autologous blood transfusion (i.e., Pre-and Post-operative autologous blood transfusion methods). Sampling method may have introduced the possibility of bias.

\section{Competing interests}

The authors declare that they have no competing interests.

\section{Authors' contributions}

\begin{tabular}{|l|c|c|c|c|}
\hline Authors' contributions & CON & MAN & ODA & IIC \\
\hline Research concept and design & $\checkmark$ & -- & -- & -- \\
\hline Collection and/or assembly of data & $\checkmark$ & -- & -- & -- \\
\hline Data analysis and interpretation & $\checkmark$ & -- & -- & -- \\
\hline Writing the article & $\checkmark$ & -- & -- & -- \\
\hline Critical revision of the article & $\checkmark$ & $\checkmark$ & $\checkmark$ & $\checkmark$ \\
\hline Final approval of article & $\checkmark$ & -- & -- & -- \\
\hline Statistical analysis & $\checkmark$ & -- & -- & -- \\
\hline
\end{tabular}

\section{Acknowledgement}

The authors wish to thank the Department of Haematology, University of Benin and Department of Obstetrics and Gynaecology, University of Port Harcourt for creating and enabling environment for this research work.

\section{Publication history}

EIC: Evangelos Terpos, University of Athens School of Medicine, Greece. Received: 20-Aug-2013 Revised: 27-Sep-2013

Accepted: 22-Oct-2013 Published: 07-Nov-2013

\section{References}

1. UNAIDS. Joint United Nations Programme on HIV/AIDS. AIDS epidemic update.November 2007. UNAIDS information centre and World Health Organisation (WHO). UNAIDS 07.27E/JC1322E.

2. WHO. Making Safe Blood Available in Africa. 2006.

3. Brooks JP and Ferrell JE. Legal and ethical considerations in the transfusion of infected or untested autologous blood. Am J Clin Pathol. 2007; 128:135-42. | Article | PubMed

4. Yomtovian R, Ceynar J, Kepner JL and Buhl M. Predeposit autologous blood transfusion: an analysis of donor attitudes and attributes. $Q R B$ Qual Rev Bull. 1987; 13:45-50. I PubMed

5. Busch MP, Young MJ, Samson SM, Mosley JW, Ward JW and Perkins HA. Risk of human immunodeficiency virus (HIV) transmission by blood transfusions before the implementation of HIV-1 antibody screening. The Transfusion Safety Study Group. Transfusion. 1991; 31:4-11. | Article | PubMed

6. Moltzan C, Proulx N, Bormanis J, Lander N, Degroot H and Rock G. Perceptions and motivations of Canadian autologous blood donors. Transfus Med. 2001; 11:177-82. | Article | PubMed
7. Lee SJ, Liljas B, Churchill WH, Popovsky MA, Stowell CP, Cannon ME and Johannesson M. Perceptions and preferences of autologous blood donors. Transfusion. 1998; 38:757-63. | Article | PubMed

8. Graham ID, Fergusson D, Dokainish H, Biggs J, McAuley L and Laupacis A. Autologous versus allogeneic transfusion: patients' perceptions and experiences. CMAJ. 1999; 160:989-95. | Article | PubMed Abstract | PubMed Full Text

9. Banning M, Bormanis J, Lander N, Neurath D and Rock G. Current perceptions of Canadian autologous blood donors. Vox Sang. 2006; 91:157-61. | Article | PubMed

10. Publications. Predeposit Autologous Transfusion Program. | Website

11. Ignatavicius D.D. and Workman M.L. Medical-surgical nursing: Patientcentred collaborative care care ( $6^{\text {th }}$ edition). Philadelphia, PA: W.B. Saunders Company. 2010.

12. Goodnough LT and Monk TG. Blood conservation in patients undergoing non-cardiac surgery. Curr Opin Anaesthesiol. 2000; 13:365-70. | Article I PubMed

13. Brecher ME and Goodnough LT. The rise and fall of preoperative autologous blood donation (editorial). Transfusion. Transfusion. 2002; 42:1618-22. | Article | PubMed

14. Schved JF. Preoperative autologous blood donation: a therapy that needs to be scientifically evaluated. Transfus Clin Biol. 2005; 12:365-9. | Article | PubMed

15. Goodnough LT, Shander A and Spence R. Bloodless medicine: clinical care without allogeneic blood transfusion. Transfusion. 2003; 43:66876. | Article | PubMed

16. Lackritz EM. Prevention of HIV transmission by blood transfusion in the developing world: achievements and continuing challenges. AIDS. 1998; 12 Suppl A:S81-6. | PubMed

17. Priuli G, Darate R, Perrin RX, Lankoande J and Drouet N. Multicentre experience with a simple blood salvage technique in patients with ruptured ectopic pregnancy in sub-Sahelian West Africa. Vox Sang. 2009; 97:317-23. | Article | PubMed

18. Ejele O.A, Mamman A, Nwabuko C.O, Chukwuonye I.I. A comparative study of CD4 positive lymphocyte count and ESR of HIV sero-positive patients at University of PortHarcourt Teaching Hospital. Pioneer Medical Journal. 2012; 2:3. I Atrticle

19. Barclay L. New Guidelines: Screen All Patients Aged 15-65 Years for HIV. Medscape. 2013.

20. Brauser D. Early Antiretroviral Therapy Shows Higher Survival Rate for HIV Patients. Medscape. 2009.

21. Walkley A. Africa: HIV Transmission Via Transfusion in Continent Remains High. 2009. I Website

22. Screening donated blood for transfusion-transmissible infection: recommendations. WHO document. 2010. I Pdf

23. Jayaraman $S$, Chalabi Z, Perel P, Guerriero $C$ and Roberts I. The risk of transfusion-transmitted infections in sub-Saharan Africa. Transfusion. 2010; 50:433-42. | Article | PubMed

24. Eldryd P, Richard G, David M. and Geoffrey G. Principles of Medicine in Africa, 3rd edition. Press syndicate. Cambridge, UK. 2004; 235-236.

\section{Citation:}

Nwabuko CO, Nnoli MA, Adaunwo OD and Chukwuonye II. Taming the tide of HIV and TTI scourge in Sub-Saharan Africa using autologous blood transfusion. Hematol Leuk. 2013; 1:7. http://dx.doi.org/10.7243/2052-434X-1-7 